\title{
Alfabetização de crianças, jovens e adultos no município de Diadema
}

\author{
ZILDA MÁRCIA GRÍCOLI IOKOI
}

$\mathrm{O}$ S DEBATES sobre alfabetização no Brasil contam com longa tradição, especialmente aqueles oriundos dos processos de letramento, centrados na inclusão social, nos quais o sujeito da ação educativa deve ser considerado como portador de um conhecimento complexo, resultado do seu vivido, da cultura, da experiência adquirida na trajetória de cada um em sua relação com o lugar e com as histórias de vida. Não seria demais relembrar os trabalhos de Maria José Werebe (1), Paulo Freire, Anísio Teixeira, que dedicaram grande parte de suas vidas na busca de soluções adequadas para o enfrentamento da questão.

Deve-se ainda ressaltar que as campanhas de alfabetização e os movimentos de ampliação das redes escolares, cujo crescimento é contínuo desde o final dos anos 60 , não eliminaram o problema do analfabetismo - como pode ser observado por censos escolares e dados do próprio Ministério da Educação que apresentam cifras elevadas - tornando o problema um desafio para todos os interessados na superação desta marca da exclusão. É inconcebível para um país como o Brasil, cujo anseio de desenvolvimento aparece nos discursos políticos de diferentes partidos, a fragilidade das políticas públicas destinadas a atender esta expectativa de direito, não seja enfrentada com a seriedade necessária.

Uma das questões analisadas neste trabalho é a da inadequação das metodologias escolares quando elas se referem ao ensino de jovens e adultos que não puderam ser escolarizados pelo sistema regular. A carência de espaços adequados, de materiais de trabalho e mesmo os preconceitos dos educadores em relação a esses alunos são significativos.

A formação dos professores, centrada em modelos homogêneos de enfrentamento da realidade escolar, via de regra aparece como um obstáculo na relação entre educadores e educandos, uma vez que o sentido preceptoral do magistério produz de imediato um afastamento entre as partes, já que os jovens e adultos possuem valores consolidados, experiências de vida desconhecidas pelos professores e formas de manifestação verbal e simbólica particulares. Deste modo, o auto-reconhecimento e a dialogia passam a ser centrais para que se crie um processo de comunicação entre as partes (2). O pensamento dialógico permite a recuperação dos elementos constitutivos da cultura popular e da erudita, que podem ser resgatadas nos muitos pontos de conexão existentes entre elas, assim como a cultura letrada e a verbal são simbioses de um reconhecimento mútuo da diversidade. 
É extremamente rico, na literatura brasileira, o diálogo entre o rural e o urbano, entre o regional e o central, entre os camponeses e os fazendeiros, entre o Norte e o Sul. De certo modo, esse diálogo complexo foi muito bem estudado pelos modernistas e, em particular, por Mário de Andrade. Mas, como ignorar as preocupações de Monteiro Lobato, traduzidas inicialmente como um movimento de incompreensão sobre o caipira, tão bem elucidado por Antonio Candido? (3). Esse encontro, entre o intelectual e as tradições, entre os contemporâneos e o passado, entre as representações e a crítica, está presente na obra de João Guimarães Rosa (4), permitindo a constituição de um rico campo lingüístico do CentroOeste brasileiro, pelo reconhecimento de um complexo de relações sociais e de o fato da cultura popular ser a chave para o entendimento do país, campo de investigações acadêmicas, com vistas a um melhor entendimento da história e do significado do povo brasileiro.

O sentido desse debate está presente nas preocupações teóricas e de pesquisa do grupo de trabalho que se organizou, de modo muito dinâmico, numa experiência de parceria entre o serviço de Educação de Diadema, o Departamento de História da Faculdade de Filosofia, Letras e Ciências Humanas da USP e a Fundação de Amparo à Pesquisa do Estado de São Paulo. A existência, nas duas pontas do sistema de demanda por alfabetização - na fase pré-escolar e na suplência de adultos -, aliada aos baixos resultados obtidos no processo educacional geral, fez com que essa parceria definisse, no programa de políticas públicas, um movimento de pesquisa que respondesse ao desafio de encontrar novos caminhos para o desenvolvimento das metas de alfabetização, relacionando num movimento de dupla mão, tanto os alfabetizandos, como os alfabetizadores, cada um dependente de conhecimentos novos sobre o outro, além de um modo especial de entender a si, aos outros e o próprio lugar. Deste movimento iniciou-se a busca de explicitação dos desejos e das necessidades de cada uma das partes envolvidas e, através do dialogo comum, a oralidade apareceu como um componente interessante no entendimento do conhecimento até então pouco explorado e mensurado na avaliação sobre a alfabetização.

Assim, a pesquisa sobre o vivido e sobre o lugar identificou as atividades de cada um dos membros do projeto, permitindo o reconhecimento da cidade (os múltiplos estudos do meio realizados) e dos estudantes (histórias de vida).

O município de Diadema, constituído por população oriunda de diferentes regiões da Europa e do Nordeste brasileiro, apresenta um cotidiano rico de experiências culturais importantes para o desenvolvimento do sentido de pertencimento e para a constituição dos vínculos identitários tão significativos no desenvolvimento educacional. Grupos de imigrantes italianos, nas décadas de 20 e 30 instalaram-se na região do Grande $\mathrm{ABC}$ como trabalhadores de olarias e de indústrias de cerâmicas, como a São Caetano; organizaram armazéns gerais, como os da família Ducca, cujas ruínas ainda são reconhecíveis pelos moradores 
daquela cidade; dedicaram-se a uma série de serviços, entre os quais os de alfaiates, sapateiros, serralheiros, marceneiros. Ao lado de alguns alemães, encontram-se ainda espanhóis, judeus do Leste europeu e, mais recentemente, um grande grupo de japoneses ocupando extensas áreas no município.

Desde os anos 40, migrantes de diferentes estados do Brasil também afluíram para aquela localidade, atraídos pelas indústrias que ali se instalaram. Estes trabalhadores foram responsáveis pelo incremento de um pólo de desenvolvimento capaz de acomodar o complexo industrial automotivo e as indústrias complementares, como o setor de autopeças, cuja pujança hoje reflui com a política de desindustrialização promovida pela abertura de mercados aos setores similares multinacionais e flexibilização tanto da estrutura produtiva reorganizada no modelo toyotista, quanto da economia garantida pelos planos Collor e Real.

Verificou-se pelo Censo de 1990 um contingente de 60\% de nordestinos na composição populacional de Diadema. Estes migrantes passaram a viver o fenômeno do não-pertencimento, uma vez que as relações afetivas, simbólicas e de reconhecimento do espaço, perdidas com o deslocamento de seus lugares de origem, deveriam ser recriadas em Diadema, compondo um novo espaço social onde o rural penetrava no urbano e o Nordeste no Sudeste. Vestimentas, alimentação, modo de falar foram sendo recriados com os valores de origem e os novos. A reinvenção das tradições permitia que o Nordeste aparecesse não como um lugar da pobreza, da seca e da fome, mas da alegria, da festa e das relações interpessoais perdidas na cidade grande, fria no clima e no acolhimento aos que chegavam de fora. Com os novos moradores, os da cidade também foram percebendo a beleza da cultura sertaneja e aprendendo novos modos de viver, comer e amar, criando elos identitários mediante novas articulações, descobertas e sociabilidades.

Deste modo pode-se perceber que, na experiência de formação da própria cidade, os espaços passaram a ser ocupados por grupos de afinidades culturais que definiram o urbano em sua concentração e expansão. Na região da represa Billings, no bairro do Eldorado, por exemplo, as primeiras ocupações foram sendo feitas por população de origem alemã, que ali se instalaram com chácaras de lazer para finais de semana. Às margens da represa, estaleiros de alemães desenvolveram uma intensa atividade náutica que, ao mesmo tempo, permitiu um grande dinamismo para o local, e sua própria desagregação, já que a ocupação se fazia sem qualquer cuidado ambiental que preservasse a área de manancial. Interessava o uso da praia, os esportes náuticos, a presença de novas formas de assimilação de trabalhadores que foram ocupar a represa do Eldorado a partir dos anos 50. O caso da família Buckup é ilustrativo desse processo e acabou estimulando um grande grupo de jovens a freqüentarem o local, como Mario, um dos seus descendentes, que representou o Brasil em atividades náuticas (5). 
A região central de Diadema, o núcleo mais antigo, foi formada a partir do loteamento que remonta à década de 20. Entre estes dois pólos, um emaranhado desordenado de tecido urbano foi se formando a partir dos fluxos migratórios da cidade dormitório que originou o município. Memória e história, fragmentos de experiências dispersas, a cidade padecia de articulação entre as várias demandase o abandono do poder público. Essas necessidades de moradia, saúde pública, saneamento e educação foram sendo expressas por articulações de movimentos sociais, que cresceram ao longo dos anos 70, no bojo da organização das lutas operárias do Grande $\mathrm{ABC}$, resultantes de longo processo de resistência operária, tanto em relação ao controle sindical quanto ao sindicalismo atrelado aos patrões e mediado pelo Estado (6).

Desse processo de exigência por serviços públicos, a educação foi um dos níveis que recebeu maior impactação, em que as reflexões críticas permitiram não apenas o entendimento da gênese dos processos de desagregação entre o morador e a cidade, mas entre os moradores e as suas experiências históricas. A estratégia de agregação permitiu a combinação dos elementos das histórias de vida e da formação da cidade na reconstituição dos nexos afirmativos de pertencimentos.

Assim, uma das metas elaboradas nesta perspectiva deveria combinar a pesquisa histórica da formação dos lugares e a história oral de vida dos moradores, de tal modo que tal encontro permitisse a formulação de projeto de alfabetização centrado nos elementos da comunicação no sentido expresso pelo pensamento educacional de Paulo Freire (7). Evidentemente, a formulação desse projeto respondeu às demandas de educadores e de diferentes mediadores, mas também, às dos cidadãos que inicialmente se manifestaram pela exigência da educação infantil, pré-escolar, como política de apoio às mães trabalhadoras (Creches e Emeis) e, posteriormente de suplência para jovens e adultos. Em ambos os casos, a formulação do projeto exigiu um debruçamento sobre o tema do alfabetizado e do analfabeto.

\section{A gênese do conceito}

Os debates sobre o analfabetismo ganharam impulso a partir dos anos 40, quando Lourenço Filho e Clementi Mariani passaram a participar de discussões para a formulação do projeto principal da Unesco de educação para a América Latina, organizado no pós-guerra. Tratava-se de um movimento dos países membros, que deveria redefinir o conceito de analfabeto, ampliando o sentido do termo para além do letramento. Das discussões oriundas dessa relação, o Brasil organizou a Campanha de Alfabetização, em 1947, cujo projeto deveria articular diferentes setores da sociedade civil na irradiação do programa, formulado para atingir três mil pessoas em todo o país. 


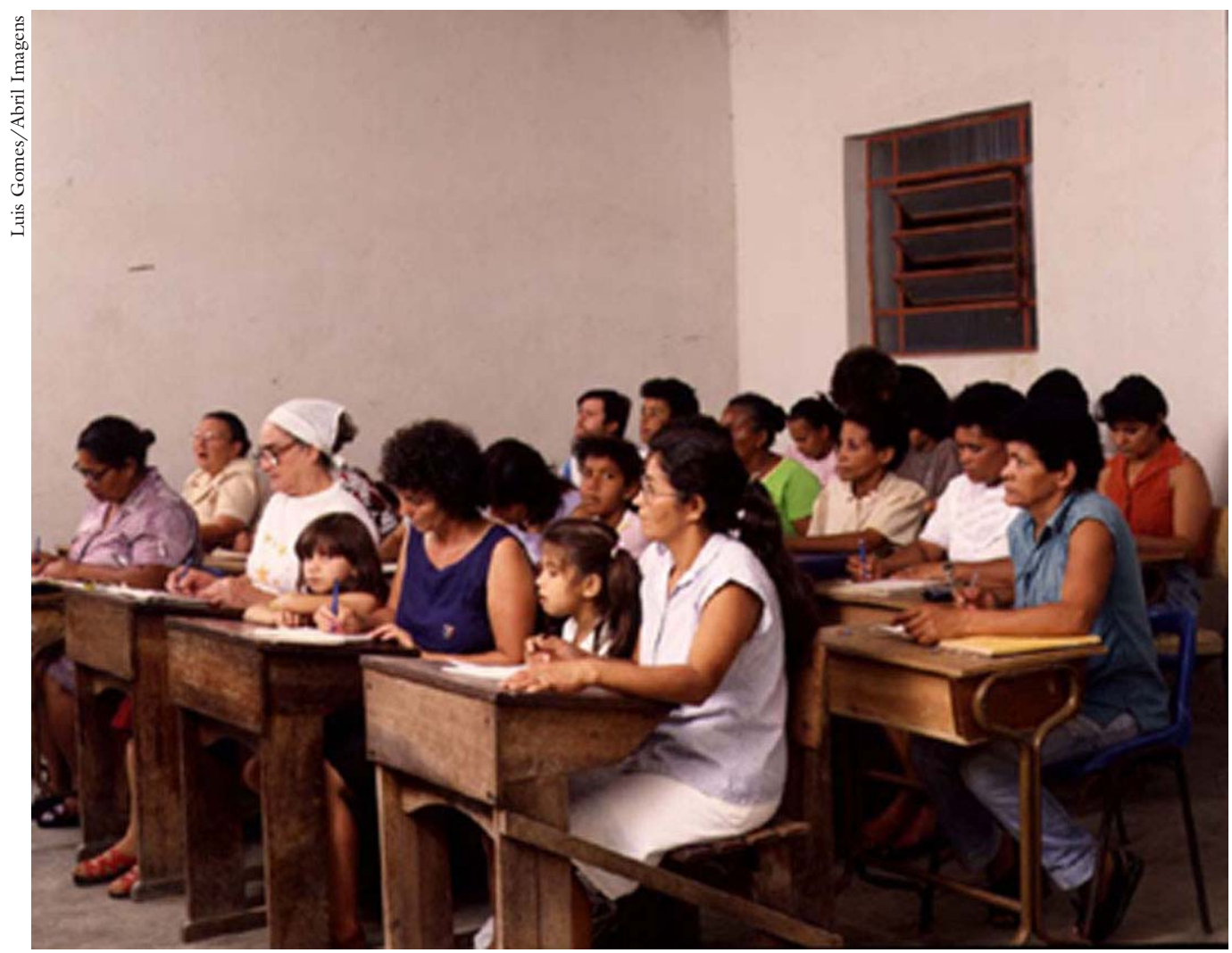

O programa dirigido pela Igreja motivou muitas discussões, entre elas o sentido de alfabetizado e analfabeto

Desse processo foi criado o Movimento de Educação de Base, pelo Ministério da Educação, na gestão Clementi Mariani, e conveniada a Igreja Católica para ser a organizadora do processo, a partir de programas de educação rural através do rádio. A Igreja estruturou, mediante um amplo sistema de monitores, as formas organizativas de um reconhecimento da realidade social do aluno, com o objetivo de estabelecer um processo comunicativo que garantisse eficácia à ação educativa.

Nesse quadro alterou-se o processo de ensino, até então organizado com vistas ao adestramento profissional, para um novo sentido à ação educativa, especialmente a partir de um outro modo de entender a relação entre o educador e o educando: como interação e troca de conhecimentos. A ação desenvolvida pelo Ministério objetivava um treinamento técnico para o trabalho, definição de valores morais e familiares na lógica do pensamento cristão, de modo a se obter um padrão de organização social que fosse mais próximo do entendimento do urbano e do sentido atribuído pelas elites culturais à civilização e ao progresso. O programa dirigido pela Igreja Católica motivou muitas discussões, entre as quais aquela encaminhada pelos próprios organismos internacionais que se esforçavam por redefinir o sentido de alfabetizado e analfabeto. 
Neste debate destacou-se o projeto desenvolvido por Paulo Freire, que propugnava um processo educacional libertador e realizador da incorporação dos valores culturais da própria população e dos elementos significativos do seu vivido, como temas centrais a serem incorporados na linguagem escrita.

Não se tratava, deste ponto de vista, de um processo iluminista que opunha civilização versus barbárie, mas do reconhecimento de atributos e valores culturais no modo de vida dos trabalhadores, camponeses, donas de casa, crianças, e de todos aqueles que compunham o complexo quadro populacional do país. Freire opunha-se à visão dual do pensamento tanto dos cepalinos quanto de outros setores da esquerda, que entendiam ser a exclusão social e cultural oriunda do modelo de desenvolvimento econômico, e não do subdesenvolvimento, decorrência do atraso das populações que se dedicavam ao trabalho rural e dos migrantes e retirantes das secas do sertão nordestino. De certo modo, os desenvolvimentistas consagravam a idéia da indolência do caipira, doente, fraco, miserável como o concebera Monteiro Lobato em obras como Urupês e Cidades Mortas, e não em sua regeneração, como em Zé Brasil.

Freire procurava apresentar um conjunto de argumentos muito significativos sobre os valores culturais e a necessidade de se construir elos de ligação identitários, positividades das muitas contribuições culturais, representadas pela vontade de potência, como a concebeu Nietzsche (8). Tais elementos sugeriam a recuperação histórica dos sujeitos culturais e sua incorporação positiva no processo de trabalho de educador/educando. Inúmeros foram os contributos do pensamento filosófico-pedagógico crítico neste reconhecimento. Na própria comissão da Unesco, Jean Piaget apresentava suas reflexões sobre os vários momentos do processo cognitivo das crianças. Dewee definia o sentido da liberdade e, em outro contexto, a pedagogia de Jänuz Korjac era estudada como possibilidade de se estruturar na educação formal um sentido de justiça, de democracia, de valorização da experiência histórica e da autoconfiança.

Esta efervescência fez com que inúmeros intelectuais organizassem debates que possibilitassem recuperar as experiências desenvolvidas, revolucionando o sentido dos projetos formulados pela Unesco para a América Latina.

Um amplo campo de disputas abriu-se, especialmente sobre a ação do Movimento de Educação de Base (MEB), que foi sendo explicitada ao longo de todo o período. Os conservadores passaram a considerá-la subversiva, especialmente pela grande adesão da população ao programa, logo no primeiro ano de seu lançamento (9). Muitos preferiam reafirmar a exclusão, a correr o risco de verem libertados os milhares de jovens e adultos excluídos da cultura letrada.

Da experiência rememorada ficou um conjunto de valores e perspectivas que hoje é parte da formação de muitos educadores. Entretanto, seu manejo concreto no processo educacional ainda não se tornou prática efetiva e, deste 
modo, a escola formal ainda padece do estranhamento dos elementos da cultura popular, e mesmo a historiografia não incorporou de modo efetivo as múltiplas experiências das camadas populares no processo de recuperação histórica. Assim, pode-se perceber que tanto os projetos, quanto as escolas vocacionais e os colégios de aplicação são práticas abortadas num processo muito embrionário pelo obscurantismo imposto pela ditadura militar, cujo caráter doutrinário e homogeneizador pode ser avaliado na introdução das modalidades de controle e delação, como efetivamente ocorreu nas escolas comunitárias do Vale do Ribeira de Iguape (10), no Mobral, ou na criação de disciplinas como Educação Moral e Cívica ou Organização Social e Política Brasileira, cujo conteúdo pretendido pode ser atestado pelos manuais didáticos disponibilizados ao público leitor das escolas, e da seleção dos regentes de aulas destas disciplinas.

Uma das questões abertas naqueles processos promoveu um amplo movimento de integração da realidade social e da cultura como elemento central no processo identitário desses sujeitos, de modo a valorizar seus anseios, interesses, escolhas, memórias e opções culturais. Neles dever-se-ia fortalecer o sentido dos direitos e não a subserviência do favor. Neles, qualificar os elos afetivos, as escolhas estéticas, o gosto culinário, de tal modo que a valorização do cotidiano permitisse trocas enriquecedoras; e que as descrições do vivido fossem transformadas em relatos, textos, desenhos e imagens fotográficas, bem como em trilhas sonoras capazes de libertar as mãos enrijecidas do trabalho, para o manejo dos materiais destinados às leituras e escritas dos adultos. Para as crianças, as histórias conhecidas e a libertação do corpo franzino e tímido com as danças, o jogo dramático e a capoeira.

\section{História local e histórias de vidas}

As várias modalidades de ensino deveriam ser pensadas numa relação dialética entre a incorporação das memórias dos sujeitos participantes e a história crítica, cujo processo analítico permitiria a incorporação/negação da dimensão particular como fenômeno geral e homogêneo. Evidentemente, esta possibilidade supunha uma revisão historiográfica de fôlego, e seu objetivo deveria envolver não apenas a comunidade dos historiadores (11), mas também movimentos sociais e educadores, a incorporação de um sentido de dever pelo reconhecimento da assimetria da relação educador/educando para se constituir a simetria cidadão/cidadão.

Este sentido tem sido perseguido pela equipe de profissionais que hoje compõem o grupo de pesquisa História Local nos Processos de Alfabetização de Crianças, Jovens e Adultos no Município de Diadema. A equipe está formada por professores, diretores, assistentes pedagógicos do serviço de educação de Diadema, alunos de graduação, de pós-graduação do Departamento de História da FFLCH da USP e historiógrafos do Centro de Memória do município, sob a minha coordenação. 
Imbuídos pela certeza da necessidade de incorporação, no processo de alfabetização, do universo cultural dos alunos, os membros da equipe passaram a buscar elementos para a construção de histórias de vida, partindo de questionamentos simples, como a história do nome dos alunos, seu lugar de origem, as lembranças mais significativas, as atividades dos pais, seus sonhos etc. Estes elementos passaram a ser centrais na busca das noções significativas das expe-riências dos alunos na introdução dos sinais gráficos, na descoberta e no reconhecimento dos múltiplos lugares de referência, nas noções de tempo, no encontro com dimensões da memória individual e coletiva das narrativas orais de pais e alunos.

A articulação entre esses elementos do vivido e a pesquisa histórica nos acervos documentais disponibilizados tanto nos museus e centros de memória dos vários municípios quanto nos arquivos do estado de São Paulo e do município de São Paulo, permitiram a recuperação da história do lugar, Diadema, e dos elos agregadores nesta cidade, de histórias de muitos lugares. Daí resultou um processo de pesquisa e a composição de uma história do município na grande região, e desta no país pelo método retrospectivo, remontando às tradições anteriores à conquista e àquelas que tiveram origem nos remotos tempos coloniais (12).

Também resultado dessa abordagem metodológica, foi definido o uso de diferentes linguagens no processo de redescoberta da relação presente/passado/ presente, expressa em fotos, desenhos, mapas, edifícios. A cultura material disponível transformou-se não apenas em ilustração de verdades discursivas, mas tornou-se material de ensino, cuja compreensão seria fundamental na relação estabelecida. Tanto do ponto de vista da técnica, como do lugar histórico e social de sua produção, a cidade e suas representações tornaram-se objetos de conhecimento. Do mesmo modo, a música, o cinema e os relatos orais passaram a constituir modalidades documentais para a organização dos programas de cursos e de crítica social. Evidentemente, nesse processo de pesquisa, as novas tecnologias puderam servir como veículos da nova postura conceitual definida, e a hipermídia auxiliou na organização do acervo disponibilizado ao usuário do projeto. Mas, o centro dessa nova abordagem foi possível pela escolha da literatura e da narrativa como elementos centrais nos procedimentos escolhidos.

\section{Contos históricos no processo de alfabetização}

Para a leitura dos alunos, optou-se pela criação de contos reunidos em dois livros Venturas e aventuras do menino Diadorim e Venturas e aventuras do 
moço Diadorim. As narrativas tecidas centradas nas histórias de vida e do lugar permitiram recuperar, na trama das tensões, os principais elementos constitutivos do imaginário social, das determinações históricas e da diversidade dos tempos em conflito contra o tempo linear do capital. Dentro do método progressivo/ regressivo, proposto por Henri Lefebvre, os contos procuram recuperar o olhar dos alunos sobre o momento presente, destacando os elementos cotidianos e a memória, ambos reveladores de suas origens. Inicia-se a aventura com o processo migratório, a chegada em São Paulo, os desafios do novo lugar e as descobertas do novo modo de viver. Deste modo procura-se dar um sentido de aventura aos elementos simples do dia a dia, colocando as experiências possibilitadas por meio do debate, da leitura, das artes plásticas, da música e do cinema em vídeo, a dramatização dos elementos constitutivos desses sujeitos históricos, para que o conhecimento sobre o fazer-se da identidade e da história abra os possíveis para a superação dos dilemas do presente. Os contos escritos para esse fim e expostos a seguir são exemplos desse processo geral de pesquisa e produção de conhecimentos a serem ensinados; são também articuladores do plano geral da escola e do projeto pedagógico escolhido.

\section{A grande viagem}

A mãe estava com tudo pronto. Não era muita coisa. Uma pequena mala do tipo caixote, embrulhada num saco de farinha branco, de modo a proteger tanto o conteúdo quanto o recipiente. Costurada na boca, deixava visível apenas a pequena alça de metal recoberta com uma pala de couro de bode, ou seria cabra? Bem, não sabia ao certo. A mulher estava ansiosa e andava bem rápido de um lado ao outro falando sem parar. Uma grande caixa com panelas de barro, os restos de farinha de macaxeira da última safra do pequeno roçado.

Diadorim também estava agitado. Nunca deixara Quixeramobim, nem andara naquela máquina barulhenta que parecia uma das muitas centopéias que ele costumava cutucar com um pauzinho, e depois de cortá-la ao meio, fazê-la corcovear como uma mula brava. morar?"

- "Maínha", disse de repente, "como é o nome do lugar onde vamos

- "Diadema", respondeu a mulher.

- “O que é isso?" Retrucou o menino.

A mãe pensou muito e arriscou...

- "Acho que é a coroa da cabeça da Santa. Uma vez meu pai contou que o poeta Suassuna escreveu um verso sobre a Diadema de Nossa Senhora dos Pretos”.

O menino, curioso, tentou imaginar um lugar que se parecesse com a 
coroa santificada. - "Então é um lugar redondo?"

- “Não sei”, respondeu.

- "Será que tem um buraco no meio?"

- "Que idéia, menino. Como as pessoas podem morar num buraco?"

- “Ah, pode sim! O padrinho Dito mora no Buraco Quente”.

- “É modo de dizer”, disse a mãe.

- "Que nada!", retrucou. "Fica mesmo num buraco, lá no fim da Gruta da Caveira!"

Que nome estranho, Gruta da Caveira pensou, sentindo um arrepio e encolhendo-se num canto.

A mãe explicou que numa das grandes secas, o gado procurava água nos grotões e acabava morrendo de fome e sede naquele lugar. Os ossos amontoados ali permaneciam visitados pelos urubus, mesmo depois das revoadas das graúnas.

Diadorim olhou o chão rachado do terreiro, o milho seco, a falta d'água.

- "Será que lá tem mato verde?" A mãe respondeu animada que o pai mandara dizer que sim, e também muita água numa tal de represa do Eldorado. Os olhos do menino brilharam.

- “Tem ouro?”, gritou. “Então porque você fica aí andando pra lá e pra cá chorando, Magna? Vamos fazer uma coroa, essa tal de Diadema, com o ouro, e trazer para a Santa daqui".

Saiu para o terreiro brincando com as palavras: "Diadema, diamante, Diadorim, diabo, dente, doente, Dorinha!"

De repente, percebeu que era a hora do compadre chegar e que ainda faltava resolver o que fazer com a cadela Bala, sua companheira de tantos folguedos que ficaria com o Chicão, seu amigo do Buraco Quente. Iriam de carroça até a Vila, de lá pegariam o caminhão de seu Zéca, o carvoeiro, até chegar a uma pequena cidade no sul da Bahia, de nome Pirapora. Dali seguiriam com um ônibus até Montes Claros em Minas Gerais. Só então entrariam, num trem rumo a São Paulo.

Sentiu o coração apertado e um pouco de medo. Como seria viver tão longe dali, não poder voltar a ver os amigos, a professora, seu padrinho que contava muitas histórias do Ceará. A saudade já doía muito e as lágrimas brotaram de seus olhos castanhos vivos e brilhantes. Entendeu a mãe e foi ao seu encontro animá-la. Afinal, desde que seu pai partira era o homem da casa e não podia deixar de proteger sua mãe. A tristeza só passou depois de três dias, quando embarcou na velha locomotiva rumo à Estação do Norte, já na grande cidade de São Paulo. 
Seu Dito recomendou enquanto embarcavam:

- “Comadre, você está seguindo para São Paulo, mas Diadema é um pouco mais distante, fica entre São Bernardo, Santo André e São Caetano do Sul”.

- "Claro Maínha”, gritou de repente o menino. "Essa Diadema é a única mulher no meio de tantos Santos que eles resolveram lhe dar uma coroa para poder namorar com ela!"

Todos riram enquanto o trem seguia com um ritmo bem definido:

Piuí, Piuí, Piuiiiiiií Café-com pão, café com pão, café com pão!

Café-com pão, café com pão, café com pão!

Ou ainda, o encontro entre o presente e o passado, a recuperação dos elementos da grande história, na pequena história, conforme pode ser lido no conto seguinte.

\section{As Memórias do avô de Neco}

- "Você já conheceu seu Dito?” Diadorim assustou-se com a pergunta de sua mãe. Não sabia que ela conhecia o homem que vivia na casa de pedra e que era o mais antigo morador do lugar.

- "Conheci na semana passada, quando fomos comer o bolo do seu aniversário", respondeu o menino com um ar desconfiado.

- "E você", perguntou olhando firme nos olhos da mãe. Ele andava com ciúmes, pois a mulher estava com um brilho novo no rosto, agora mais alegre e arrumada.

- "Você sabia que ele é africano? Chegou ao Brasil em 1887, um ano antes de acabar a escravidão. Ele nasceu em um navio negreiro".

- "Que tipo de navio é este", perguntou o menino.

- "Eram navios que seguiam para a África levando tecidos, tintas e vários mantimentos, trazendo os negros para as Américas, para serem vendidos como escravos".

- "Por que fizeram isto com as pessoas?", questionou Diadorim com os olhos arregalados. A mãe respondeu que era para ganhar dinheiro. $\mathrm{O}$ menino ficou indignado. Lembrou-se de todos os amigos negros e de seus familiares, e sentiu um aperto no peito.

A mulher continuou narrando uma história triste, repleta de choro de homens, mulheres e crianças arrancados de suas aldeias e vilas, aferrados com grilhões e colocados nos porões dos navios, como animais, para trabalharem nas plantações da cana, algodão, criação de gado ou extração de minérios das 
várias regiões do Brasil e das Américas.

- "Seu Dito escapou de ser jogado no mar quando, do navio em que sua mãe viajava, avistou-se o navio inglês que vigiava as embarcações carregadas de escravos e as afundava. Ficou escondido dentro de um cesto, em baixo dos panos das velas rebaixadas. Sua mãe, pressentindo o perigo, deixou o pequeno ali, quando os soldados portugueses os obrigavam a pularem em alto mar para despistar os ingleses.

Segundo soube quando cresceu, um dos marujos o encontrou ao aportaram no Rio de Janeiro. Gostou daquele negrinho recém-nascido e ficou com ele em seu cortiço no Largo da Candelária.

Um ano depois, com a abolição da escravatura, o marujo batizou o pequeno com o nome de Benedito de Castro Lima, e levou-o para muitos lugares enquanto viajava. Depois, acabou transferindo-se para São Paulo, para trabalhar no Porto de Santos e o menino ficou sendo seu mascote. Quando um belo dia resolveu se casar, a noiva aceitou a presença de Dito desde que ele se tornasse um serviçal do casal.

Dito acabou tornando-se jardineiro e ficou com o marujo até completar 16 anos. Depois disto, foi para Santo André da Borda do Campo empregando-se numa olaria. Conheceu Nilza e casou-se com ela. Teve sete filhos, três netos e 15 bisnetos".

Um deles é Neco, amigo de Diadorim, que muitas vezes contou para a turma que seu bisavô nascera num navio. $\mathrm{O}$ menino nunca pensou que fosse tão triste a história dos escravos.

Naquela noite sonhou com os escravos sendo atirados no mar e morrendo afogados. Acordou suado, quando a mãe o chamou para a escola.

As perspectivas disponibilizadas pelos contos históricos são muito estimuladoras, uma vez que a leitura e a problematização estabelecida em cada um deles permite não apenas a recuperação das emoções, mas um processo contínuo de reflexões e da descoberta do pertencimento, pelas afirmações positivas entre experiências que permitem o fazer-se dos sujeitos sociais. $\mathrm{Na}$ perspectiva thompsoniana, é o reencontro de um novo modo de produzir e pensar a história. Dela decorrem todos os outros componentes curriculares no processo de alfabetização, sempre centrado na relação entre o vivido e o concebido.

Conclui-se neste processo, que se realiza também na perspectiva educacional, um reencontro com fértil momento de debates e de projetos experimentais interrompidos na década de 60 pelo golpe militar. Mais ainda, como todo o projeto contou com o aporte de novas tecnologias, os materiais 
de pesquisa foram inseridos num Cd-Rom hipermídia, cuja estrutura em três dimensões permitiu a instalação dos contos no espaço de uma das escolas do projeto e a incorporação da produção dos alunos nas imagens e no cancioneiro do CD (13).

Notas

1 M.J. Werebe, Grandezas e misérias do ensino no Brasil. São Paulo, Difusão Européia do Livro, 1968.

2 Paulo Freyre, Extensão ou comunicação? Rio de Janeiro, Paz e Terra, 1975.

3 Mario de Andrade, Macunaima. São Paulo, Livraria Martins Editora, 1944; Monteiro Lobato, Mister Slang e o Brasil. Rio de Janeiro, Cia. Ed. Nacional, 1927; Antonio Candido, Os parceiros do Rio Bonito. Rio de Janeiro, José Olympio, 1964.

4 João Guimarães Rosa, Grande sertão: veredas. Rio de Janeiro, José Olympio, 1965; Manuelzão e Miguilin. Rio de Janeiro, Nova Fronteira, 1984.

5 Mario Buckup foi campeão paulista, brasileiro e latino-americano de velas.

6 Leia-se Amnéris Maroni, Estratégia da recusa. São Paulo, Brasiliense, 1982; Ricardo Antunes, Rebeldia do trabalho. São Paulo, Cia das Letras, 1986; Eder Sader, Quando novos personagens entram em cena. Rio de Janeiro, Paz e Terra, 1988.

7 FREIRE, Paulo. Pedagogia do Oprimido. São Paulo, Brasiliense, 1978.

8 G. Nietzsche, La Gaia Ciencia. México, Siglo XXI, 1976.

9 O programa destinava-se a três mil pessoas, mas foram inscritas 10 mil no lançamento da campanha, o que revela uma expectativa de direito ignorada pelos próprios mediadores. Sobre o Projeto Principal e a Campanha, veja-se C.M. Souza, Nenhum brasileiro fora da escola. São Paulo, 1999. Dissertação (mestrado), FFLCH-USP.

10 M.C. Martinez, Superfície e subterrâneo: projetos governamentais no Vale do Ribeira. São Paulo, 1996. Dissertação (mestrado), FFLCH-USP.

11 Entendemos comunidade dos historiadores no sentido atribuído por B. Anderson, Nação e consciência nacional. São Paulo, Ática, 1989.

12 Essa recuperação foi possível por projetos de iniciação científica bem recortados, cuja monografia final destina-se à composição de livro acadêmico dirigido aos professores e interessados na história do lugar. Sete estudantes de história, financiados por Fapesp e Pibic/CNPq realizaram, sob a minha orientação, as monografias mencionadas, capítulos do livro Diadema nasceu no Grande ABC: história retrospectiva da Cidade Vermelha. São Paulo, Humanitas/FFLCH-USP/Fapesp, 2001.

13 Todo o material compôs um kit distribuído para as escolas da rede municipal de Diadema, com 20 pranchas de mapas geográficos e históricos, 20 pranchas fotográficas de diferentes momentos, um livro acadêmico, dois livros de leituras, um guia do 
usuário, com todas as discussões teórico-metodológicas das diferentes linguagens utilizadas e um Cd-Rom. Além disso, está em curso um processo de avaliação da proposta e dos materiais em rede. Para participar desse processo acesse o site www.diadorim.org.br .

Zilda Márcia Grícoli Iokoi, professora do Departamento de História da FFLCH-USP, é presidente da Associação Nacional de História (ANPUH) e coordenadora do projeto de pesquisa História local nos processos de alfabetização de crianças, jovens e adultos no município de Diadema, financiado pela Fapesp no período de 1996/2000. 